\title{
Recent Advances in Plasma Catalysis (ISPCEM 2016)
}

\author{
Zhou-jun Wang ${ }^{1}$ Ben W.-L. Jang ${ }^{2} \cdot$ Chang-jun Liu ${ }^{3}$
}

Published online: 6 April 2017

(C) Springer Science+Business Media New York 2017

The series of International Symposium on Plasma for Catalyses and Energy Materials (ISPCEM) found its origin in 2012 and take place biannually in Tianjin, China [1, 2]. The aim of the symposia is to provide a platform for scientists and students who are working on the combination of plasma technology and catalyst or nano energy material to exchange ideas, to discuss future development and to promote collaboration. 93 participants from 12 countries attended ISPCEM-2016 attracted, reflecting its international collaboration nature.

On the basis of the results presented at ISPCEM-2016, this themed Topics in Catalysis issue entitled "Recent Advances in Plasma Catalysis (ISPCEM 2016)" is organized and published. The contents of the present issue comprise three reviews and 19 original papers. The reviews overviewed recent advances in the following areas: (1) plasmas in contact with liquids for chemical processing and material synthesis [3]; (2) non-colloidal nanocatalysts

Zhou-jun Wang

wangzj@mail.buct.edu.cn

Ben W.-L. Jang

ben.jang@tamuc.edu

Chang-jun Liu

coronacj@tju.edu.cn

1 State Key Laboratory of Chemical Resource Engineering, Beijing University of Chemical Technology, 15 Beisanhuan East Road, Beijing 100029, China

2 Department of Chemistry, Texas A\&M UniversityCommerce, 2600 South Neal St., Commerce, TX 75429-3011, USA

3 Tianjin Co-Innovation Center of Chemical Science \& Engineering, School of Chemical Engineering and Technology, Tianjin University, 92 Weijin Road, Tianjin 300072, China fabricated using arc plasma deposition for heterogeneous catalysis and photocatalysis [4]; (3) carbon surface modifications by plasma for catalyst support and electrode materials [5]. The original papers cover different areas of plasma application for catalyses and energy materials, which can be categorized by topics as: (1) reforming of methane [6-9]; (2) conversion of CO [10-14]; (3) environmental processes [15-21]; (4) hydrogenation and hydrochlorination reactions [22-24]. This themed issue provides a picture of recent advances in plasma catalysis, which should be of significant interest in both academic and industrial scientists of all disciplines using plasma technology and/or catalysts. We hope that this themed issue would give new directions and trigger further progress and collaboration in the related fields.

The editors would like to thank the editorial team of Topics in Catalysis for the opportunity to publish this themed issue and their kind assistance during preparation. We wish to thank all of the authors and reviewers who have contributed to this themed issue. We also acknowledge the excellent work of the international advisory board and organizing committee members. Having enjoyed the successful ISPCEM-2016, we look forward to the next edition of the symposium, which will take place in Tianjin, China in September of 2018.

\section{References}

1. Jang BW-L, Liu C-J, Endres F, Nozaki T (2013) Recent advances in plasma and catalysis (ISPCEM 2012). Catal Today 211:1

2. Nozaki T, Neyts EC, Ostrikov K, Liu C-J (2015) Plasmas for enhanced catalytic processes (ISPCEM 2014). Catal Today 256:1-2 
3. Rumbach P, Go DB (2017) Perspectives on plasmas in contact with liquids for chemical processing and materials synthesis. Top Catal 60:1. doi:10.1007/s11244-017-0745-9 (this issue)

4. Kim SH, Moon S-Y, Park JY (2017) Non-colloidal nanocatalysts fabricated using arc plasma deposition and their application in heterogenous catalysis and photocatalysis. Top Catal 60:2. doi:10.1007/s11244-017-0746-8 (this issue)

5. Zhang L, Sadanandam G, Liu X, Scurrell MS (2017) Carbon surface modifications by plasma for catalyst support and electrode materials applications. Top Catal 60:3. doi:10.1007/s11244-0170747-7 (this issue)

6. Lian J, Fang X, Liu W, Huang Q, Sun Q, Wang H, Wang X, Zhou W (2017) Ni supported on $\mathrm{LaFeO}_{3}$ perovskites for methane steam reforming: on the promotional effects of plasma treatment in $\mathrm{H}_{2}$-Ar atmosphere. Top Catal 60:4. doi:10.1007/s11244-0170748-6 (this issue)

7. Rahem N, Haghighi M, Babaluo AA, Allahyari S, Estifaee P, Jafari MF (2017) Plasma-assisted dispersion of bimetallic Ni-Co over $\mathrm{Al}_{2} \mathrm{O}_{3}-\mathrm{ZrO}_{2}$ for $\mathrm{CO}_{2}$ reforming of methane: influence of voltage on catalytic properties. Top Catal 60:5. doi:10.1007/ s11244-017-0749-5 (this issue)

8. Lu N, Bao X, Jiang N, Shang K, Li J, Wu Y (2017) Non-thermal plasma-assisted catalytic dry reforming of methane and carbon dioxide over G- $\mathrm{C}_{3} \mathrm{~N}_{4}$-based catalyst. Top Catal 60:6. doi:10.1007/s11244-017-0750-z (this issue)

9. Ray D, Reddy PMK, Challapalli S (2017) Glass beads packed DBD-plasma assisted dry reforming of methane. Top Catal 60:7. doi:10.1007/s11244-017-0751-y (this issue)

10. Zhao B, Chen Z, Yan X, Ma X, Hao Q (2017) CO methanation over $\mathrm{Ni} / \mathrm{SiO}_{2}$ catalyst prepared by ammonia impregnation and plasma decomposition. Top Catal 60:8. doi:10.1007/s11244017-0752-x (this issue)

11. Yan X, Bao J, Zhao B, Yuan C, Hu T, Huang C, Li Y (2017) $\mathrm{CO}$ dissociation on $\mathrm{Ni} / \mathrm{SiO}_{2}$ : the formation of different carbon materials. Top Catal 60:9. doi:10.1007/s11244-017-0754-8 (this issue)

12. Kardash TY, Slavinskaya EM, Gulyaev RV, Zaikovskii AV, Novopashin SA, Boronin AI (2017) Enhanced thermal stability of $\mathrm{Pd} / \mathrm{Ce}-\mathrm{Sn}-\mathrm{O}$ catalysts for $\mathrm{CO}$ oxidation prepared by plasmaarc synthesis. Top Catal 60:10. doi:10.1007/s11244-017-0755-7 (this issue)

13. Zhu B, Liu J-L, Li X-S, Liu J-B, Zhu X, Zhu A-M (2017) Insitu regeneration of $\mathrm{Au}$ nanocatalysts by atmospheric-pressure air plasma: regeneration characteristics of square-wave pulsed plasma. Top Catal 60:11. doi:10.1007/s11244-017-0756-6 (this issue)
14. Di LB, Duan DZ, Park D-W, Ahn W-S, Lee B-J, Zhang XL (2017) Cold plasma for synthesizing high performance bimetallic $\mathrm{PdCu}$ catalysts: effect of reduction sequence and $\mathrm{Pd} / \mathrm{Cu}$ atomic ratios. Top Catal 60:12. doi:10.1007/s11244-017-0757-5 (this issue)

15. Gholipour A, Rahemi N, Allahyari S, Ghareshabani E (2017) Hybrid plasma-catalytic oxidation of VOCs with NiMn/montmorillonite: plasma and catalyst considerations. Top Catal 60:13. doi:10.1007/s11244-017-0758-4 (this issue)

16. Sudhakaran MSP, Trinh HQ, Karuppiah J, Hossian MM, Mok YS (2017) Plasma catalytic removal of p-xylene from air stream using $\gamma-\mathrm{Al}_{2} \mathrm{O}_{3}$ supported manganese catalyst. Top Catal 60:14. doi:10.1007/s11244-017-0759-3 (this issue)

17. Misumi S, Yoshida H, Matsumoto A, Hinokuma S, Sato T, Machida M (2017) Thermal evolution of the structure and activity of Rh overlayer catalysts prepared by pulsed arc-plasma deposition. Top Catal 60:15. doi:10.1007/s11244-017-0760-x (this issue)

18. Tatchemo FWB, Nzali S, Youbi GK, Djowe AT, Saa DK, Acayanka E, Laminsi S, Gaigneaux EM (2017) Gliding arc plasma synthesis of $\mathrm{MnO}_{2}$ nanorods for the plasma-catalytic bleaching of azoïc Amaranth Red dye. Top Catal 60:16. doi:10.1007/ s11244-017-0761-9 (this issue)

19. Shang K, Wang X, Li J, Wang H, Jiang N, Lu N, Wu Y (2017) Effect of persulfate on the degradation of Acid Orange 7 (AO7) by dielectric barrier discharge plasma. Top Catal 60:17. doi:10.1007/s11244-017-0762-8 (this issue)

20. Zhang X, Li Z, Zhan Z, Di L (2017) Preparation of F-doped $\mathrm{TiO}_{2}$ photocatalysts by gas-liquid plasma at atmospheric pressure. Top Catal 60:1. doi:10.1007/s11244-017-0763-7 (this issue)

21. Wang W, Li X, Wang A, Sun Z, Chen Y (2017) Plasma synthesis of $\mathrm{Ni}_{2} \mathrm{P}$ from mixtures of $\mathrm{NiCl}_{2}$ and hypophosphites. Top Catal 60:19. doi:10.1007/s11244-017-0764-6 (this issue)

22. Li Y, Jang BW-L (2017) Selective hydrogenation of acetylene over $\mathrm{Pd} / \mathrm{Al}_{2} \mathrm{O}_{3}$ catalysts: effect of non-thermal RF plasma preparation methodologies. Top Catal 60:20. doi:10.1007/s11244017-0765-5 (this issue)

23. Guo Z, Huang Q, Luo S, Chu W (2017) Atmospheric discharge plasma enhanced preparation of $\mathrm{Pd} / \mathrm{TiO}_{2}$ catalysts for acetylene selective hydrogenation. Top Catal 60:21. doi:10.1007/s11244017-0766-4 (this issue)

24. Dai H, Zhu M, Zhao D, Yu F, Dai B (2017) Effective catalytic performance of plasma-enhanced $\mathrm{W}_{2} \mathrm{~N} / \mathrm{AC}$ as catalysts for acetylene hydrochlorination. Top Catal 60:22. doi:10.1007/s11244017-0767-3 (this issue) 